Correspondence

Henrik Christensen

henrik.christensen@vetmi.kvl.dk

\section{Emended description of porcine [Pasteurella] aerogenes, [Pasteurella] mairii and [Actinobacillus] rossii}

\author{
Henrik Christensen, ${ }^{1}$ Peter Kuhnert, ${ }^{2}$ Magne Bisgaard, ${ }^{1}$ Reinier Mutters, ${ }^{3}$ \\ Francis Dziva ${ }^{4} \dagger$ and John Elmerdahl Olsen ${ }^{1}$
}

\author{
${ }^{1}$ Department of Veterinary Microbiology, The Royal Veterinary and Agricultural University, \\ Stigbøjlen 4, 1870 Frederiksberg C, Denmark \\ ${ }^{2}$ Institute of Veterinary Bacteriology, University of Bern, Laenggass-Strasse 122, Bern, \\ Switzerland \\ ${ }^{3}$ Institut für Medizinische Mikrobiologie und Krakenhaushygiene, Philipps-Universität, Marburg, \\ Germany \\ ${ }^{4}$ University of Zimbabwe, Harare, Zimbabwe
}

\begin{abstract}
The aim of this study was to improve the definition and identification of a group of veterinarily important bacteria referred to as the [Pasteurella] aerogenes-[Pasteurella] mairii-[Actinobacillus] rossii complex. These organisms have mainly been isolated from the reproductive and intestinal tracts of pigs and in most cases have been considered as opportunistic pathogens. A collection of 87 strains were characterized by phenotypic analysis from which 41 strains were selected for 16S rRNA gene sequence comparison, out of which 23 have been sequenced in the present study. One group of 21 strains phenotyped as biovars 1, 3-5, 9-11, 19 and 25-27, including the type strain of $[P$.$] aerogenes, showed 16 \mathrm{~S}$ rRNA gene sequence similarities of $99.6 \%$ or higher; another group of 18 strains including biovars 2, 6-8, 12-15, 21, 23, 24 and 26A and the type strain of [A.] rossii showed $97 \cdot 8 \%$ or higher $16 \mathrm{~S}$ rRNA gene sequence similarity. Between the two groups, 93.8-95.7\% 16S rRNA gene sequence similarity was observed. Strains of $[P$.] mairii showed $99 \cdot 5 \%$ similarity, with $95 \cdot 5-97 \cdot 2$ and $93 \cdot 8-95 \cdot 5 \%$ similarity to strains of $[P$.$] aerogenes and [A$.] rossii, respectively. Four strains could not be classified with any of these groups and belonged to other members of Pasteurellaceae. Comparisons were also made to DNA-DNA hybridization data. Biovars 1, 9, 10, 11 and 19, including the type strain of $[P$.$] aerogenes, linked at 70 \%$ DNA reassociation, whereas strains identified as biovars 2,6 , $7,8,12,15$ and 21 of $[P$.$] aerogenes linked at 81 \%$. The latter group most likely represents $[A$.$] rossii based on the 16 \mathrm{~S}$ rRNA gene sequence comparisons. DNA reassociation between the $[P$.] aerogenes and $[A$.] rossii groups was at most $37 \%$, whereas $47 \%$ was the highest DNA reassociation found between $[P$.] aerogenes and $[P$.] mairii. The study showed that $[P$.] aerogenes, $[P$.] mairii and $[A$.] rossii can not be easily separated and may consequently be misidentified based on current knowledge of their phenotypic characteristics. In addition, these taxa are difficult to separate from other taxa of the Pasteurellaceae. A revised scheme for separation based upon phenotypic characters is suggested for the three species $[P$.$] aerogenes emend., [P$.$] mairii$ emend. and $[A$.$] rossii emend., with the respective type strains ATCC 27883^{\top}$, NCTC $^{10699^{\top}}$ and ATCC $27072^{\top}$.
\end{abstract}

Published online ahead of print on 6 August 2004 as DOI 10.1099/ ijs.0.63119-0.

tPresent address: Institute for Animal Health, Compton, Newbury, Berks, UK.

The GenBank/EMBL/DDBJ accession numbers of $16 \mathrm{~S}$ rRNA gene sequences described in this report are AY465357-AY465374 and AY431030-AY431033, as listed in Table 1 and Fig. 2.

Supplementary tables showing the DNA reassociation data are available in IJSEM Online.
[Pasteurella] aerogenes was established as a species in 1974 (McAllister \& Carter, 1974) and subsequently included in the Approved Lists (Skerman et al., 1980). The species has been excluded from Pasteurella sensu stricto on the basis of genotypic studies, which is the reason for enclosing the genus name in brackets (Mutters et al., 1989). Presently, $[P$.] aerogenes seems rather heterogeneous. Twenty-three biovars were reported by Bisgaard (1993) and five DNA clusters outlined by Böhme (1993). Four additional biovars 
have subsequently been outlined. The species was initially isolated from the intestines, kidney and nose of necropsy specimens from piglets and young swine in the USA and found associated with diarrhoea and other bacterial infections (McAllister \& Carter, 1974). Only a single isolate of $[P$.$] aerogenes from a pig fetus was considered as a primary$ pathogen in the first report (McAllister \& Carter, 1974). Later on, Fodor et al. (1991) also reported the bacterium isolated from a pig fetus in Hungary. The origins of pig isolates from Belgium were in accordance with the initial description; however, the bacteria were also reported from vaginal exudates of sows (Hommez \& Devriese, 1976). In the 1990s, it was concluded that most isolates of $[P$.] aerogenes were obtained from pathological lesions and that the ecology of the species was poorly known (Bisgaard, 1993). More recently $[P$.] aerogenes has been identified from human infections related to pig bites (Lindberg et al., 1998).

rRNA-DNA hybridizations have shown that $[P$.] aerogenes was most closely related to Pasteurella multocida (De Ley et al., 1990). This relationship was not confirmed by $16 \mathrm{~S}$ rRNA phylogenetic analysis, since 16S rRNA phylogenetic analysis of the family Pasteurellaceae showed that $[P$.] aerogenes, [Pasteurella] mairii and [Actinobacillus] seminis formed a monophyletic unit defined as the Seminis cluster (cluster 14) (Olsen et al., 2004).

[P.] mairii (Bisgaard taxon 19) was proposed as a separate species by Sneath \& Stevens (1990). The species was named on basis of nine strains isolated from pigs and one strain isolated from a prairie marmot (Sneath \& Stevens, 1985). Previous studies found $[P$.] aerogenes and $[P$.] mairii to be related by DNA-DNA hybridization at $46 \%$ DNA reassociation (Mutters et al., 1985). [P.] mairii has also been suggested to be excluded from Pasteurella sensu stricto (Mutters et al., 2004).

[Actinobacillus] rossii was established by Sneath \& Stevens (1990) on the basis of an unnamed bacterial taxon represented by 10 strains isolated from pigs (Sneath \& Stevens, 1985), including four strains originally described by Ross et al. (1972). [A.] rossii could only be separated unequivocally from $[P$.$] aerogenes by acid production from sucrose$ according to their descriptions (Sneath \& Stevens, 1985, 1990).

Misidentification of $[A$.$] rossii and [P$.$] aerogenes occurs$ frequently when reference is made to $16 \mathrm{~S}$ rRNA gene sequence comparison. The $16 \mathrm{~S}$ rRNA gene comparison of Olsen et al. (2004) found strains MCCM 01550 and MCCM 01551 (listed as P.sp.2 and 1989-5477, respectively, in Table 1) to be related to the type strain of [A.] rossii in accordance with the present study despite their phenotypic identification as $[P$.] aerogenes. $16 \mathrm{~S}$ rRNA phylogenetic analysis also showed that the type strain of [A.] rossii was closely related to [Actinobacillus] porcinus (Christensen et al., 2003). Further studies of virulence and pathogenicity are dependent on an improved classification, including a correct identification of [A.] rossii.
The RTX toxin (pax gene) was found in four strains of $[P$.] aerogenes isolated from aborted or young piglets. All strains with the pax gene showed more than $99.6 \%$ similarity to the type strain of $[P$.] aerogenes as inferred by $16 \mathrm{~S}$ rRNA gene sequence comparison. These strains were haemolytic on sheep-blood agar and CAMP-positive, whereas haemolytic activity was not observed in strains without the pax gene (Kuhnert et al., 2000). Unfortunately, previous descriptions of $[P$.] aerogenes do not include CAMP-test data, and bovine blood was used rather than ovine blood. Another representative of the RTX toxin family was found in the type strain of [A.] rossii (Schaller et al., 2000). Both genes showed similarity to the apxII and apxIII genes of Actinobacillus pleuropneumoniae. The RTX toxins of these organisms might represent a major virulence factor; however, further studies of their impact on pathogenicity and phylogenetic relationships remain to be performed. Such studies of virulence and pathogenicity have to await improved classification and identification of these organisms.

The aim of the present study consequently was to improve the classification of $[P$.$] aerogenes, [P$.$] mairii and [A$.$] rossii$ by comparing phenotypic results with genotypic characterization mainly obtained by $16 \mathrm{~S}$ rRNA gene sequence analysis and DNA-DNA hybridizations.

\section{Bacterial strains and phenotypic characterization}

Eighty-nine strains including reference strains were selected for the study based upon previous reports on phenotypic (Bisgaard, 1993) and DNA-DNA hybridization (Ursing, 1981; Böhme, 1993) data (Table 1). Further phenotypic characterization was performed according to Bisgaard et al. (1991) including separation into biovars based on 17 characters variable within bacteria previously recognized as $[P$.] aerogenes (Table 2). Only some of the biotyped strains were included in the present genotypic investigation. The type strain of $[A$.$] porcinus was also phenotyped to allow$ comparison with $[P$.$] aerogenes, [P$.$] mairii, [A$.$] rossii and$ $[A$.$] seminis. [A.] porcinus was cultivated on chocolate agar.$

\section{RAPD characterization}

Ten strains of $[P$.$] mairii and 13$ strains of $[A$.$] rossii (Table 1$ ) were characterized in order to select representative strains for $16 \mathrm{~S}$ rRNA gene sequence comparison. For additional comparison, the type strains of the species $[P$.] aerogenes, $[P$.$] mairii, [A$.$] rossii and [A$.$] seminis were included. Cells$ were cultivated in brain heart infusion broth (Difco) and DNA was isolated as described by Christensen et al. (1993). DNA was dried and redissolved in water of Millipore quality and the concentration was determined by spectrophotometry (GeneQuant; Pharmacia Biotech). PCR amplification was performed by the Ready-To-Go RAPD analysis kit (Amersham Biosciences) as described previously (Dziva et al., 2001). Primer three (5'-GTAGACCCCGT) was selected for the study to give few and distinct bands on the basis of 
Table 1. Strains and biovars of the $[P$.$] aerogenes-[P.] mairii-[A.] rossii complex investigated$

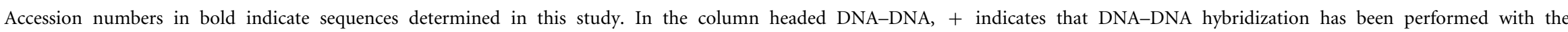
strain. In the column headed RAPD, I-VI refer to the RAPD profiles shown in Fig. 1. ND, Not determined.

\begin{tabular}{|c|c|c|c|c|c|c|c|}
\hline Strain & Phenotype & $\begin{array}{l}\text { Genotype }(16 S \\
\text { rRNA-based } \\
\text { identification) }\end{array}$ & Origin/disease & Country* & $\begin{array}{l}\text { 16S rRNA gene } \\
\text { accession no. }\end{array}$ & $\begin{array}{l}\text { DNA- } \\
\text { DNA }\end{array}$ & RAPD \\
\hline $\begin{array}{l}\text { ATCC } 27883^{\mathrm{T}}\left(=\mathrm{P} 634^{\mathrm{T}}=\text { CIP } 80.14^{\mathrm{T}}=\text { CCUG }\right. \\
9995^{\mathrm{T}}=\text { CCUG } 27904^{\mathrm{T}}=\text { DSM } 10153^{\mathrm{T}} \\
\left.=\text { McAllister P } 172-71^{\mathrm{T}}\right)\end{array}$ & [P.] aerogenes biovar 1 & {$[P$.$] aerogenes$} & Pig, intestine & USA & M75048, U66491 & + & I \\
\hline $\mathrm{BA} 151 \cdot 1(=$ P.a.14 $)$ & {$[P$.$] aerogenes biovar 1$} & $\mathrm{ND}$ & Pig, lung & $\mathrm{B}$ & ND & + & ND \\
\hline JF1319 (=P1290/94) & {$[P$.$] mairii$} & {$[P$.$] aerogenes$} & Pig, placenta/abortion & $\mathrm{CH}$ & U66492 & ND & ND \\
\hline JF2118 (=P325/98) & [P.] mairii & {$[P$.$] aerogenes$} & Pig, placenta/abortion & $\mathrm{CH}$ & AF139578 & ND & ND \\
\hline JF2032 (=99/890) & Unclassified & {$[P$.$] aerogenes$} & Piglet/sepsis & $\mathrm{CH}$ & AF139580 & ND & ND \\
\hline P.a.9 (= BA27.5) & {$[P$.$] aerogenes biovar 3$} & ND & Pig, tonsil & $\mathrm{B}$ & ND & ND & ND \\
\hline JF2185 ( = P772/98) & {$[P$.$] aerogenes biovar 3$} & {$[P$.$] aerogenes$} & Pig, bronchus/pneumonia & $\mathrm{CH}$ & AF139586 & ND & ND \\
\hline F147 & {$[P$.$] aerogenes biovar 4$} & $\mathrm{ND}$ & Rabbit, pneumonia & DK & $\mathrm{ND}$ & ND & $\mathrm{ND}$ \\
\hline JF2011 ( = P811/97) & {$[P$.$] aerogenes biovar 4$} & {$[P$.$] aerogenes$} & Pig, intestine/diarrhoea & $\mathrm{CH}$ & AF139577 & $\mathrm{ND}$ & $\mathrm{ND}$ \\
\hline JF2034 (=99/968) & {$[P$.$] aerogenes biovar 4$} & {$[P$.$] aerogenes$} & Pig, intestine/diarrhoea & $\mathrm{CH}$ & AF139581 & ND & ND \\
\hline JF2039 ( = P894/97) & {$[P$.$] aerogenes biovar 4$} & {$[P$.$] aerogenes$} & Pig, liver/sepsis & $\mathrm{CH}$ & AF139582 & ND & ND \\
\hline$J F 2101(=99 / 1449)$ & {$[P$.$] aerogenes biovar 4$} & {$[P$.$] aerogenes$} & Pig, intestine/diarrhoea & $\mathrm{CH}$ & AF139585 & ND & ND \\
\hline$J F 2154(=$ P577/98) & {$[P$.$] aerogenes biovar 4$} & {$[P$.$] aerogenes$} & Pig, bronchus/pneumonia & $\mathrm{CH}$ & AF139587 & ND & ND \\
\hline C5527 & {$[P$.$] aerogenes biovar 5$} & {$[P$.$] aerogenes$} & Pig, lymph node & DK & AY465371 & ND & ND \\
\hline $3214 / 88$ & {$[P$.$] aerogenes biovar 9$} & ND & Human, pig bite & UK & ND & + & ND \\
\hline JF2072 ( = P28/98) & {$[P$.$] aerogenes biovar 9$} & {$[P$.$] aerogenes$} & Pig, liver/sepsis & $\mathrm{CH}$ & AF139584 & ND & ND \\
\hline P591 $(=$ T748 = McAllister SS-185-72) & {$[P$.$] aerogenes biovar 10$} & {$[P$.$] aerogenes$} & Pig & USA & AY465372 & + & ND \\
\hline G5223/1 & {$[P$.$] aerogenes biovar 10$} & ND & Pig, lung & $\mathrm{AU}$ & $\mathrm{ND}$ & ND & ND \\
\hline P592 (=T749= McAllister SS-7-73) & {$[P$.$] aerogenes biovar 11$} & {$[P$.$] aerogenes$} & Pig & USA & AY465373 & + & ND \\
\hline P593 ( = T750 = McAllister SS-68-73) & {$[P$.$] aerogenes biovar 11$} & ND & Pig & USA & ND & + & ND \\
\hline BK1778/4 (= MCCM 01523) & [P.] aerogenes biovar 19 & ND & Pig & B & $\mathrm{ND}$ & + & ND \\
\hline JF2006 ( = P787/97 $)$ & [P.] aerogenes biovar 19 & {$[P$.$] aerogenes$} & Pig fetus, aborted & $\mathrm{CH}$ & AF139579 & ND & ND \\
\hline $\mathrm{JF} 2419(=\mathrm{B} 96 / 34)$ & {$[P$.$] aerogenes biovar 25$} & {$[P$.$] aerogenes$} & Dog, liver & B & AY465357 & ND & ND \\
\hline $\mathrm{JF} 2420(=4-97=97 \mathrm{AV} 121)$ & {$[P$.$] aerogenes biovar 26$} & {$[P$.$] aerogenes$} & Pig, joint & $\mathrm{B}$ & AY465358 & ND & ND \\
\hline $\mathrm{JF} 2142(=\mathrm{P} 542 / 98)$ & {$[P$.$] aerogenes biovar 27$} & {$[P$.$] aerogenes$} & Pig, intestines, diarrhoea & $\mathrm{CH}$ & AF139583 & ND & ND \\
\hline $\begin{array}{l}\text { NCTC } 10699^{\mathrm{T}}\left(=\text { CCUG } 27189^{\mathrm{T}}=\mathrm{P} 637^{\mathrm{T}} \dagger\right. \\
\left.=\text { Mair } 5143 / 70^{\mathrm{T}}\right)\end{array}$ & [P.] mairii (Bisgaard taxon 19) & {$[P$.$] mairii$} & Pig fetus & UK & AF024532 & + & II \\
\hline P646 (= Mair 14679/70) & {$[P$.$] mairii$} & ND & Pig & UK & ND & ND & II \\
\hline P639 (= Mair 18286/70) & {$[P$.$] mairii$} & ND & Pig & UK & ND & ND & II \\
\hline P640 (= Mair 34152/70) & {$[P$.$] mairii$} & ND & Pig & UK & ND & ND & II \\
\hline Past. 9 & {$[P$.$] mairii$} & ND & Pig & $\mathrm{B}$ & ND & ND & ND \\
\hline P638 $(=$ NCTC $10700=$ Mair $7385 / 70)$ & {$[P$.$] mairii$} & ND & Pig uterus & UK & ND & ND & II \\
\hline
\end{tabular}


Table 1. cont.

\begin{tabular}{|c|c|c|c|c|c|c|c|}
\hline Strain & Phenotype & $\begin{array}{l}\text { Genotype (16S } \\
\text { rRNA-based } \\
\text { identification) }\end{array}$ & Origin/disease & Country & $\begin{array}{l}\text { 16S rRNA gene } \\
\text { accession no. }\end{array}$ & $\begin{array}{l}\text { DNA- } \\
\text { DNA }\end{array}$ & RAPD \\
\hline $34152 / 71$ & {$[P$.$] mairii$} & $\mathrm{ND}$ & Pig & UK & ND & ND & II \\
\hline $27694 / 74$ & {$[P$.$] mairii$} & ND & Pig fetus & UK & ND & ND & II \\
\hline $34310 / 72$ & {$[P$.$] mairii$} & {$[P$.$] mairii$} & Piglet & UK & AY431033 & ND & II \\
\hline Past. 4 & [P.] mairii & ND & Pig, liver & $\mathrm{B}$ & ND & ND & ND \\
\hline $9801 / 75$ & {$[P$.$] mairii$} & {$[P$.$] mairii$} & Pig & UK & AY431032 & $\mathrm{ND}$ & II \\
\hline $\begin{array}{l}\mathrm{JF} 2082^{\mathrm{T}}\left(=\mathrm{A} 55^{\mathrm{T}}=\mathrm{A} 68^{\mathrm{T}}=\mathrm{Ross} 192^{\mathrm{T}}=\mathrm{P} 624^{\mathrm{T}}\right. \\
=\text { ATCC } 27072^{\mathrm{T}}=\text { CCUG } 12395^{\mathrm{T}}=\text { CCUG } \\
24851^{\mathrm{T}}=\text { CIP } 102634^{\mathrm{T}}=\text { NCTC } 10801^{\mathrm{T}} \\
\left.=\text { MCCM } 02461^{\mathrm{T}}\right)\end{array}$ & [A.] rossii & [A.] rossii & Pig, vaginal exudate & USA & AF224289 & $\mathrm{ND}$ & IV \\
\hline P.sp.2 ( = MCCM 01551) & {$[P$.$] aerogenes biovar 2$} & [A.] rossii & Pig bone & B & AF224290 & + & $\mathrm{ND}$ \\
\hline JF2424 $(=$ P595 $=$ T573 = McAllister SS-187-74 $)$ & {$[P$.$] aerogenes biovar 6$} & [A.] rossii & Pig & USA & AY465362 & + & ND \\
\hline A150 & {$[P$.$] aerogenes biovar 7$} & $\mathrm{ND}$ & Pig & UK & ND & ND & ND \\
\hline P.24 (=JF2167) & {$[P$.$] aerogenes biovar 7$} & [A.] rossii & Pig, brain & $\mathrm{B}$ & AY465365 & + & $\mathrm{ND}$ \\
\hline 1989-5477 (=MCCM 01550) & {$[P$.$] aerogenes biovar 8$} & [A.] rossii & Pig abortion & $\mathrm{C}$ & AF224288 & + & $\mathrm{ND}$ \\
\hline $\mathrm{X} 116-92$ & {$[P$.$] aerogenes biovar 8$} & $\mathrm{ND}$ & Goose, pneumonia/airsacculitis & ND & $\mathrm{ND}$ & $\mathrm{ND}$ & $\mathrm{ND}$ \\
\hline $266 / 1961$ & {$[P$.$] aerogenes biovar 8$} & $\mathrm{ND}$ & Pig lung & $\mathrm{B}$ & $\mathrm{ND}$ & ND & $\mathrm{ND}$ \\
\hline $1989-145$ & {$[P$.$] aerogenes biovar 8$} & $\mathrm{ND}$ & Pig vagina & $\mathrm{C}$ & $\mathrm{ND}$ & ND & $\mathrm{ND}$ \\
\hline P.a.6 (=BA354.6) & [P.] aerogenes biovar 12 & $\mathrm{ND}$ & Pig tonsil & $\mathrm{B}$ & ND & ND & $\mathrm{ND}$ \\
\hline P.a.11 (=BA18M/4) & {$[P$.$] aerogenes biovar 12$} & $\mathrm{ND}$ & Pig tonsil & B & ND & $\mathrm{ND}$ & $\mathrm{ND}$ \\
\hline BA657/3 & {$[P$.$] aerogenes biovar 12$} & [A.] rossii & Pig & B & ND & + & ND \\
\hline P.a.5 (=BA354.5) & {$[P$.$] aerogenes biovar 12$} & [A.] rossii & Pig tonsil & B & AY465369 & ND & $\mathrm{ND}$ \\
\hline 3920.2 & {$[P$.$] aerogenes biovar 13$} & [A.] rossii & Pig lung & $\mathrm{B}$ & Same as AY465360 & ND & ND \\
\hline P.a.12 (=BA84.11) & {$[P$.$] aerogenes biovar 14$} & [A.] rossii & Pig tonsil & B & AY465368 & ND & ND \\
\hline P.a.7 (=BA151.7) & {$[P$.$] aerogenes biovar 15$} & [A.] rossii & Pig liver & B & AY465367 & + & $\mathrm{ND}$ \\
\hline BK2661/4 & {$[P$.$] aerogenes biovar 21$} & $\mathrm{ND}$ & Pig lung & B & $\mathrm{ND}$ & + & $\mathrm{ND}$ \\
\hline JF2120 & {$[P$.$] aerogenes biovar 21$} & [A.] rossii & Piglet & $\mathrm{CH}$ & AY465364 & ND & $\mathrm{ND}$ \\
\hline 1 Hommez & {$[P$.$] aerogenes biovar 23$} & $\mathrm{ND}$ & ND & $\mathrm{ND}$ & $\mathrm{ND}$ & & \\
\hline JF2425 $(=$ B96/45) & {$[P$.$] aerogenes biovar 23$} & [A.] rossii & Pig, intestine & $\mathrm{B}$ & AY465363 & $\mathrm{ND}$ & $\mathrm{ND}$ \\
\hline 96 AV2015 $(=4071.2=3-97=J F 2422)$ & [P.] aerogenes biovar 24 & [A.] rossii & Pig, lung & $\mathrm{B}$ & AY465360 & ND & ND \\
\hline$J F 2073$ & {$[P$.$] aerogenes biovar 26 \mathrm{~A}$} & [A.] rossii & Piglet & $\mathrm{CH}$ & AY465366 & ND & $\mathrm{ND}$ \\
\hline JF1390 & [A.] rossii & [A.] rossii & Aborted pig fetus & $\mathrm{CH}$ & AF025839 & ND & $\mathrm{ND}$ \\
\hline JF1989 & [A.] rossii & $\mathrm{ND}$ & Aborted pig fetus & $\mathrm{CH}$ & $\mathrm{ND}$ & $\mathrm{ND}$ & $\mathrm{ND}$ \\
\hline JF2033 & [A.] rossii & $\mathrm{ND}$ & Pig & $\mathrm{CH}$ & $\mathrm{ND}$ & $\mathrm{ND}$ & $\mathrm{ND}$ \\
\hline $\mathrm{JF} 2102$ & [A.] rossii & $\mathrm{ND}$ & Pig uterus & $\mathrm{CH}$ & $\mathrm{ND}$ & $\mathrm{ND}$ & $\mathrm{ND}$ \\
\hline JF2163 & [A.] rossii & $\mathrm{ND}$ & Aborted pig fetus & $\mathrm{CH}$ & $\mathrm{ND}$ & $\mathrm{ND}$ & $\mathrm{ND}$ \\
\hline $46377 / 76$ & [A.] rossii & $\mathrm{ND}$ & Pig & UK & $\mathrm{ND}$ & $\mathrm{ND}$ & $\mathrm{V}$ \\
\hline $41304 / 76$ & [A.] rossii & $\mathrm{ND}$ & Pig & UK & ND & ND & $\mathrm{V}$ \\
\hline
\end{tabular}


Table 1. cont.

\begin{tabular}{|c|c|c|c|c|c|c|c|}
\hline Strain & Phenotype & $\begin{array}{l}\text { Genotype (16S } \\
\text { rRNA-based } \\
\text { identification) }\end{array}$ & Origin/disease & Country $^{\star}$ & $\begin{array}{l}\text { 16S rRNA gene } \\
\text { accession no. }\end{array}$ & $\begin{array}{c}\text { DNA- } \\
\text { DNA }\end{array}$ & RAPD \\
\hline P.a.1 & [A.] rossii & $\mathrm{ND}$ & Pig, lung & $\mathrm{B}$ & ND & ND & $\mathrm{V}$ \\
\hline $6887 / 76$ & [A.] rossii & [A.] rossii & Aborted pig fetus & UK & AY431030 & ND & $\mathrm{V}$ \\
\hline $32587 / 74$ & [A.] rossii & $\mathrm{ND}$ & Aborted pig fetus & UK & $\mathrm{ND}$ & ND & VI \\
\hline $48057 / 75$ & [A.] rossii & ND & Pig & UK & ND & ND & VI \\
\hline $16688 / 74$ & [A.] rossii & [A.] rossii & Pig & UK & AY431031 & ND & VI \\
\hline Ross 63 (=ATCC 27073) & [A.] rossii & $\mathrm{ND}$ & Pig & USA & ND & ND & IV \\
\hline Ross 145 & [A.] rossii & ND & Pig & USA & ND & ND & IV \\
\hline BK2705.1 & [A.] rossii & ND & Pig & ND & ND & ND & IV \\
\hline P.a.8 & [A.] rossii & ND & Porcine vaginal discharge & ND & ND & ND & IV \\
\hline BL428.1 & [A.] rossii & ND & Pig & ND & ND & ND & IV \\
\hline Past. 22 & [A.] rossii & ND & Pig, vaginal exudate & B & ND & ND & IV \\
\hline Past. 1 & [A.] rossii & ND & Pig, liver & B & ND & ND & ND \\
\hline Past. 6 & [A.] rossii & ND & Pig & $\mathrm{B}$ & ND & ND & ND \\
\hline $51811 / 78$ & {$[P$.$] aerogenes biovar 16$} & $\mathrm{ND}$ & Dog eye & UK & $\mathrm{ND}$ & + & ND \\
\hline B96/12 ( = JF2421) & {$[P$.$] aerogenes biovar 16$} & A. equuli subsp. equuli & Pig lung & B & AY465359 & ND & ND \\
\hline JF2423 ( = P.a.3 = BA354.1 $)$ & {$[P$.$] aerogenes biovar 17$} & Taxon 10 & Pig tonsil & B & AY465361 & ND & ND \\
\hline $5-97$ & {$[P$.$] aerogenes biovar 17$} & $\mathrm{ND}$ & Horse intestine & DK & $\mathrm{ND}$ & ND & ND \\
\hline BA543/4 & {$[P$.$] aerogenes biovar 17$} & ND & Pig & $\mathrm{B}$ & ND & ND & ND \\
\hline BA436.5 & {$[P$.$] aerogenes biovar 18$} & Taxon 10 & Pig & B & AY465374 & + & ND \\
\hline BA597.9 & {$[P$.$] aerogenes biovar 20$} & M. varigena-like & Pig & B & AY465370 & + & ND \\
\hline 20 pig & {$[P$.$] aerogenes biovar 22$} & ND & Pig & ND & ND & ND & ND \\
\hline ATCC $15768^{\mathrm{T}}$ & [A.] seminis & [A.] seminis & Ovine semen & $\mathrm{AU}$ & M75047 & $\mathrm{ND}$ & III \\
\hline
\end{tabular}

${ }^{*} \mathrm{AU}$, Australia; B, Belgium; C, Canada; CH, Switzerland. DK, Denmark.

$\dagger$ Strain $\mathrm{P} 637^{\mathrm{T}}$ was received and characterized under three different numbering systems; Frederiksen $\left(\mathrm{P} 637^{\mathrm{T}}\right)$, Sneath $\left(\mathrm{NCTC} 10699^{\mathrm{T}}\right)$ and $\mathrm{Mair}\left(5143 / 70^{\mathrm{T}}\right)$. 
Table 2. Phenotypic characters used for separation of biovars of the $[P$.$] aerogenes-[P.] mairii-[A.] rossii complex$

Symbols:,$+ 90 \%$ or more strains positive within $1-2$ days; $(+), 90 \%$ or more strains positive within $3-14$ days;,$- 90 \%$ or more strains negative within 14 days; d, $11-89 \%$ positive, W, weakly positive.

\begin{tabular}{|c|c|c|c|c|c|c|c|c|c|c|c|c|c|c|c|c|c|c|c|c|c|c|c|c|c|c|c|c|}
\hline \multirow[t]{2}{*}{ Character } & \multicolumn{11}{|c|}{$[P$.$] aerogenes (sensu 16 \mathrm{~S}$ rRNA) } & \multicolumn{13}{|c|}{ [A.] rossii (sensu 16S rRNA) } & \multicolumn{4}{|c|}{$\begin{array}{l}\text { Excluded or not analysed } \\
\quad(\text { sensu } 16 \mathrm{~S} \text { rRNA })\end{array}$} \\
\hline & 1 & 3 & 4 & 5 & 9 & 10 & 11 & 19 & 25 & 26 & 27 & 2 & 6 & 7 & 8 & 12 & 13 & 14 & 15 & 21 & 23 & 24 & $26 \mathrm{~A}$ & 16 & 17 & 18 & 20 & 22 \\
\hline Catalase & + & + & + & + & + & + & + & + & + & + & + & + & + & + & $\mathrm{d}$ & - & - & W & + & $\mathrm{d}$ & - & - & + & - & $\mathrm{d}$ & - & + & - \\
\hline Ornithine & - & + & + & - & + & + & + & + & + & - & + & - & - & - & - & - & - & - & - & - & - & - & - & - & - & - & + & - \\
\hline Indole & - & - & - & - & - & - & - & - & - & - & - & - & - & + & - & + & + & + & - & - & - & + & - & - & - & - & - & - \\
\hline (+)-D-Arabitol & - & - & - & - & - & - & - & - & - & - & - & - & - & - & - & - & - & - & - & - & - & - & - & + & - & - & - & - \\
\hline (+)-L-Arabinose & + & + & + & - & - & + & + & + & + & + & - & + & - & + & + & + & $\mathrm{W}$ & + & + & + & + & + & + & - & + & + & + & + \\
\hline (+)-D-Xylose & + & + & + & + & + & + & - & + & - & + & - & + & + & + & - & - & - & + & - & + & + & - & - & + & + & + & + & + \\
\hline meso-Inositol & + & - & + & + & + & + & + & + & - & + & + & - & $\mathrm{W}$ & + & + & + & $(+)$ & $(+)$ & + & + & + & + & - & - & - & - & $\mathrm{W}$ & - \\
\hline (-)-D-Mannitol & - & - & - & - & - & - & - & + & - & - & - & - & + & + & + & + & + & + & + & + & + & + & + & + & - & - & + & + \\
\hline (-)-D-Sorbitol & - & - & - & - & - & - & - & - & - & - & - & - & + & + & + & - & + & + & + & + & + & + & - & - & - & - & - & - \\
\hline$(+)$-D-Glucose, gas & + & + & + & + & + & $\mathrm{d}$ & + & + & + & - & + & + & + & + & + & + & + & + & - & + & + & + & + & + & + & + & - & + \\
\hline (+)-L-Rhamnose & - & - & - & - & - & + & - & - & - & + & - & - & - & - & - & - & - & - & + & - & - & - & - & - & + & - & $(+)$ & + \\
\hline (+)-D-Melibiose & - & - & - & - & - & - & - & - & - & - & - & - & - & - & - & + & + & + & + & - & + & + & - & + & + & + & - & + \\
\hline$\alpha$-Galactosidase & - & - & - & - & - & - & - & - & - & - & - & - & - & - & - & + & + & + & + & - & + & + & - & + & + & + & - & + \\
\hline Trehalose & - & - & - & - & - & - & - & - & - & - & - & - & - & - & - & - & - & - & - & - & - & - & - & + & + & + & - & + \\
\hline ONPX & - & - & - & - & - & - & - & + & - & - & - & - & - & - & - & $\mathrm{W}$ & - & $(+)$ & - & $\mathrm{d}$ & - & - & $\mathrm{W}$ & - & $(+)$ & - & - & $\mathrm{w}$ \\
\hline NPG & - & - & - & - & - & - & - & + & - & - & - & - & - & - & - & - & - & - & - & - & - & - & - & - & - & - & $\mathrm{w}$ & - \\
\hline PGUA & - & - & - & - & - & - & - & + & - & - & - & - & - & - & - & - & - & - & - & - & - & - & - & - & - & - & - & - \\
\hline $\begin{array}{l}\text { Strains characterized pheno- } \\
\text { typically }(n)\end{array}$ & 3 & 4 & 15 & 1 & 3 & 2 & 2 & 2 & 1 & 1 & 1 & 1 & 1 & 6 & 4 & 4 & 1 & 1 & 1 & 2 & 1 & 1 & 1 & 1 & 3 & 1 & 1 & 1 \\
\hline $\begin{array}{l}\text { Strains characterized by } 16 \mathrm{~S} \\
\text { rRNA gene sequence }(n)\end{array}$ & 1 & 1 & 5 & 1 & 1 & 1 & 1 & 1 & 1 & 1 & 1 & 1 & 1 & 1 & 1 & 1 & 1 & 1 & 1 & 1 & 1 & 1 & 1 & 1 & 1 & 1 & 1 & 0 \\
\hline
\end{tabular}




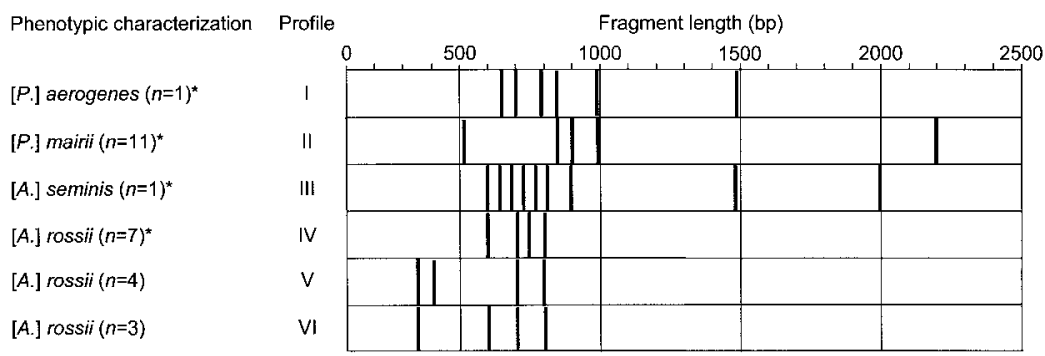

Fig. 1. RAPD analysis of strains of $[P$. mairii and $[A$.$] rossii in comparison with the$ type strains of $[P$.$] aerogenes and [A$.] seminis. Asterisks indicate groups that include the type strain of the stated species.

screening with the primers included in the kit against the type strain of [A.] rossii and a strain of [P.] aerogenes. The amplified fragments were resolved on agarose gels and stained in ethidium bromide for visualization.

Four groups, each with an identical profile, were found in addition to separate profiles for the type strains of $[P$. aerogenes and [A.] seminis (Fig. 1). The distribution of strains within the four RAPD types is shown in Table 1. Between four (types IV-VI) and nine (type III) fragments were observed. No fragments were in common between the profiles II ([P.] mairii) and IV-VI ([A.] rossii), underlining the genotypic diversity of these taxa. Eleven strains of $[P$.] mairii including the type strain included under two different designations formed group II, while 14 strains representing [A.] rossii formed groups IV (seven strains including the type strain), V (four strains) and VI (three strains) (Table 1; Fig. 1). Up to four fragments with sizes of approx. 350, 600, 650, 700, 750, 800, 850, 900, 1000 and $1500 \mathrm{bp}$ were shared between the profiles. Types IV-VI with strains of [A.] rossii shared fragments of 350, 600, 700 and $800 \mathrm{bp}$. None of the four type strains of [P.] aerogenes, $[P$.] mairii, [A.] rossii and [A.] seminis shared a profile. Three additional strains of [A.] seminis (CCUG 18730, CCUG 18731 and CCUG 23440) not included in the present study shared a profile and differed from the type strain in two fragments (data not shown).

\section{Sequencing of 16S rRNA genes}

The $[P$.$] aerogenes-[P.] mairii-[A.] rossii complex was re-$ evaluated on the basis of genotypic comparison of $16 \mathrm{~S}$ rRNA gene sequences and DNA-DNA hybridization. Strains were grouped based upon similarity to the type strains of $[P$.$] aerogenes, [P$.$] mairii and [A.] rossii as well$ as to other species of Pasteurellaceae. On the basis of this grouping, the phenotypic characteristics of the three species were re-evaluated (Tables 1-3). DNA-DNA reassociation data are available as two supplementary tables in IJSEM Online.

16S rRNA gene sequence analysis of 23 strains (Table 1) was performed as outlined previously (Angen et al., 1998; Kuhnert et al., 2000; Christensen et al., 2002). These analyses were performed in different laboratories by common cyclesequencing protocols. Strain BA436.5 was found difficult to analyse because of inter-operon differences.
Searches for 16S rRNA gene sequences were performed by BLAST (Altschul et al., 1997) at GenBank. Pairwise sequence comparisons were performed by BESTFIT (Wisconsin Sequence Analysis Package, GCG) and multiple alignments made by PILEUP (GCG). Maximum-likelihood analysis was performed by fastDNAmL including bootstrap analysis (Felsenstein, 1981; Olsen et al., 1994) on a Linux-compatible server. Maximum-parsimony analysis was performed by PHYLIP (Felsenstein, 1995).

Phylogenetic analysis based on 16S rRNA gene sequence comparison showed 17 strains to be closely related to the type strain of $[P$.] aerogenes, with high support for their common node by bootstrap analysis and parsimony analysis (Fig. 2). These 17 strains represented organisms identified phenotypically as [P.] aerogenes biovars $3(n=1), 4(5)$, $5(1), 9(1), 10(1), 11(1), 19$ (1), 25 (1), 26 (1) and 27 (1) in addition to $[P$.] mairii (2) and an unclassified strain, and showed $99.6 \%$ or higher $16 \mathrm{~S}$ rRNA gene sequence similarity to the type strain of $[P$.] aerogenes (biovar 1 ). Strains JF2419 and JF2420 shared sequences with the previously deposited strains JF2011, JF2101, JF2154 and JF2039 under the accession numbers AF139577, AF139585, AF139587 and AF139582 (these strains had identical sequences). Strains P591 and P592 shared sequences with strain JF2072, previously deposited under accession no. AF139584. Strain C5527 shared a sequence with strain JF2034, previously deposited under accession no. AF139581.

Two strains, both of which were classified as [P.] mairii based upon phenotypic characters, showed 99.5 and $99.9 \%$ $16 \mathrm{~S}$ rRNA gene similarity, respectively, to the type strain of $[P$.] mairii, and this group was also well supported. The $[P$.] mairii group was closely related to the type strain of $[A$.$] seminis, and the three species [P$.$] aerogenes, [P$.$] mairii$ and $[A$.$] seminis formed a monophyletic group (Seminis)$ in accordance with the published phylogeny (Christensen et al., 2003; Olsen et al., 2004).

Fifteen strains were related to the type strain of [A.] rossii and formed a monophyletic group (Fig. 2). These strains represented organisms classified phenotypically as biovars $2,6-8,12-15,21,23,24$ and $26 \mathrm{~A}$ of $[P$.] aerogenes, each represented by a single isolate. Members of this group showed $97 \cdot 8 \%$ or higher $16 \mathrm{~S}$ rRNA gene sequence similarity to the type strain of $[A$.] rossii and the group was then slightly more diverse than was observed for the strains 
Table 3. Phenotypic characters that separate $[P$.$] aerogenes, [P$.$] mairii, [A$.$] seminis, [A$.$] rossii and [A$.] porcinus

Symbols:,$+ 90 \%$ or more strains positive within 1-2 days; $(+), 90 \%$ or more strains positive within $3-14$ days; -, $90 \%$ or more strains negative within 14 days; d, 11-89\% positive; W, weak reaction. Reactions of the type strains are given in brackets. For isolate-dependent characters, percentages of positive strains are given in parentheses.

\begin{tabular}{|c|c|c|c|c|c|}
\hline Character & $\begin{array}{c}{[P .] \text { aerogenes }(21} \\
\text { strains), biovars } 1, \\
3-5,9-11,19,25-27\end{array}$ & $\begin{array}{l}{[P .] \text { mairii }} \\
(8 \text { strains })\end{array}$ & $\begin{array}{c}\text { [A.] seminis } \\
\text { ATCC } 15768^{\mathrm{T}}\end{array}$ & $\begin{array}{c}{[A .] \text { rossii (18 strains), }} \\
\text { biovars } 2,6-8,12-15 \\
21,23,24,26 \mathrm{~A}\end{array}$ & $\begin{array}{l}\text { [A.] porcinus } \\
\text { CCUG } 38924^{\mathrm{T}}\end{array}$ \\
\hline Catalase & + & + & + & $\mathrm{d}[+](67)$ & - \\
\hline Oxidase & $\mathrm{d}[+](81)$ & $\mathrm{d}[-](38)$ & - & $\mathrm{d}[+](78)$ & $\mathrm{W}$ \\
\hline$\beta$-Haemolysis (bovine blood) & - & $-[\mathrm{W}]$ & - & $-[+](6)$ & - \\
\hline Methyl red, $37^{\circ} \mathrm{C}$ & $\mathrm{d}[-](19)$ & - & - & $\mathrm{d}[-](39)$ & $\mathrm{W}$ \\
\hline Ornithine decarboxylase & $\mathrm{d}[-](81)$ & + & + & - & - \\
\hline Indole & - & - & - & $\mathrm{d}[\mathrm{W}](50)$ & - \\
\hline Phosphatase (NaOH detection) & $-(5)$ & ND & - & - & + \\
\hline Phosphatase $\left(\mathrm{NH}_{3}\right.$ detection $)$ & $-(5)$ & + & - & $-(6)$ & + \\
\hline Growth on MacConkey agar & $+(90)$ & - & - & $\mathrm{d}[\mathrm{w}](28)$ & $\mathrm{W}$ \\
\hline Glycerol & $+/(+)$ & $\mathrm{d}[-](13)$ & - & $+/(+)(94)$ & - \\
\hline (+)-D-Arabitol & - & $\mathrm{d}[+](75)$ & - & $\mathrm{d}[-](17)$ & - \\
\hline$(+)$-L-Arabinose & $\mathrm{d}[+](81)$ & + & $\mathrm{W}$ & $+(94)$ & - \\
\hline$(-)$-D-Arabinose & $+/(+)$ & - & - & $\mathrm{d}[-](83)$ & + \\
\hline$(+)$-D-Xylose & $\mathrm{d}[+](81)$ & + & $\mathrm{W}$ & $\mathrm{d}[+](56)$ & + \\
\hline meso-Inositol & $+(90)$ & $+/(+)$ & $\mathrm{W}$ & $\mathrm{d}[+](89)$ & + \\
\hline (-)-D-Mannitol & $\mathrm{d}[-](24)$ & + & $\mathrm{W}$ & $+(94)$ & + \\
\hline (-)-D-Sorbitol & - & + & - & $\mathrm{d}[+](78)$ & + \\
\hline (+)-D-Glucose, gas & $\mathrm{d}[+](86)$ & - & - & $\mathrm{d}[+](78)$ & - \\
\hline (+)-D-Mannose & + & + & - & $\mathrm{d}[-](89)$ & + \\
\hline (+)-L-Rhamnose & $-(9)$ & - & - & $\mathrm{d}[+](11)$ & - \\
\hline NPG ( $\beta$-glucosidase $)$ & $\mathrm{d}[-](24)$ & + & + & $\mathrm{d}[+](22)$ & - \\
\hline Lactose & $+/(+)(95)$ & - & - & $+/(+)$ & + \\
\hline Maltose & $+(90)$ & - & - & $\mathrm{d}[-](78)$ & + \\
\hline$(+)$-D-Melibiose & - & - & - & $\mathrm{d}[-](39)$ & + \\
\hline Sucrose & $+/(+)$ & + & - & $\mathrm{d}[-](83)$ & + \\
\hline Raffinose & $\mathrm{d}[-](29)$ & - & - & $\mathrm{d}[-](78)$ & + \\
\hline Dextrin & $+(90)$ & - & - & $\mathrm{d}[-](78)$ & + \\
\hline Aesculin, Fe & $\mathrm{d}[-](24)$ & $(+)$ & - & - & - \\
\hline$\alpha$-Galactosidase & - & - & - & $\mathrm{d}[-](39)$ & + \\
\hline PGUA ( $\alpha$-glucuronidase) & $\mathrm{d}[-](24)$ & + & + & $\mathrm{d}[+](22)$ & - \\
\hline ONPX ( $\beta$-xylosidase $)$ & $\mathrm{d}[-](24)$ & $\mathrm{d}[+](88)$ & + & $\mathrm{d}[+](41)$ & - \\
\hline
\end{tabular}

related to [P.] aerogenes. The species [A.] rossii and [A.] porcinus were related (Porcinus) (Christensen et al., 2003) (Fig. 2). Strains representing the two groups $[P$.] aerogenes and $[A$.] rossii showed $93 \cdot 8-95 \cdot 2 \% 16 \mathrm{~S}$ rRNA gene sequence similarity. Between $[P$.] aerogenes and $[P$.$] mairii strains,$ $95 \cdot 3-97 \cdot 2 \%$ similarity was found, while strains of $[A$.$] rossii$ and $[P$.] mairii showed $93 \cdot 9-95 \cdot 5 \%$ similarity.

Strains representing biovars $16,17,18$ and 20 of $[P$. aerogenes were found to be unrelated to the $[P$.] aerogenes$[P$.] mairii- $[$ A.] rossii complex by $16 \mathrm{~S}$ rRNA gene sequence comparison. The non-haemolytic but CAMP-positive strain B96/12 of biovar 16 was related to the type strain of Actinobacillus equuli subsp. equuli (accession no. M75072) with $99.9 \%$ similarity. Strains JF2423 and BA436.5, respectively from biovars 17 and 18, showed $98.9 \% 16 \mathrm{~S}$ rRNA gene sequence similarity to taxon 10 (strain CCUG 15572, accession no. AF024528), a taxon closely related to [Actinobacillus] succinogenes (Christensen et al., 2003; Olsen et al., 2004). Strain BA597.9 of biovar 20 was found to be variable in haemolysis, but showed a positive CAMP reaction and was $98-100 \%$ similar in the $16 \mathrm{~S}$ rRNA sequence to strains of Mannheimia varigena (accession nos AF053893, AF053899, U57076).

\section{DNA-DNA hybridization}

DNA-DNA hybridizations between 10 strains in nine pairs were performed according to the spectrophotometric method as described previously (Mutters et al., 1985). Further data on DNA-DNA hybridization were reported by Böhme (1993) (spectrophotometric method) 


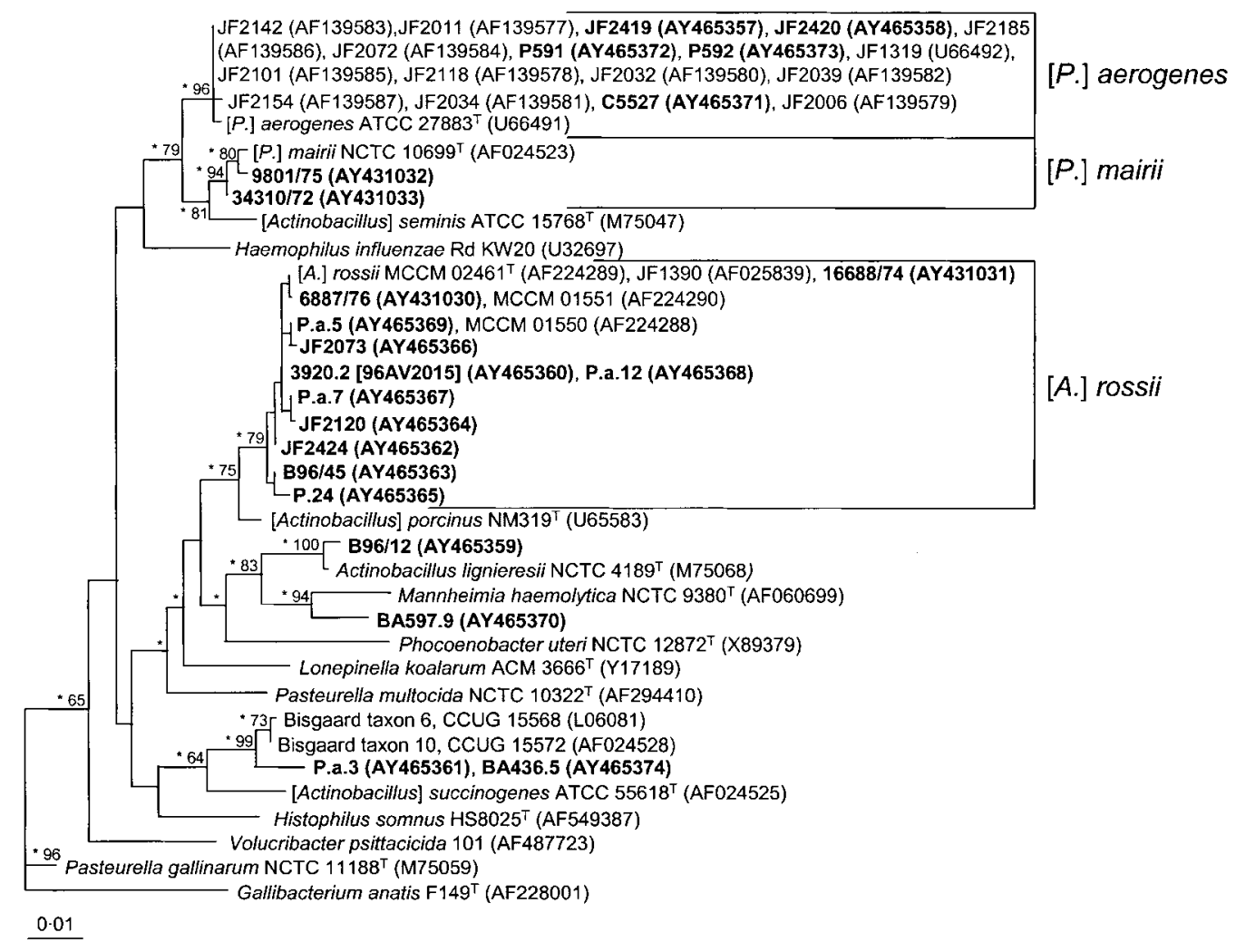

Fig. 2. Phylogenetic relationships between the taxa of the $[P$.$] aerogenes -[P$.] mairii- $[A$.$] rossii complex and representative$ members of the Pasteurellaceae based on maximum-likelihood analysis of $16 \mathrm{~S}$ rRNA gene sequences. Support for monophyletic groups by bootstrap analysis is indicated as percentages for values higher than 50 and nodes also observed by maximum-parsimony are indicated by asterisks. Strains in bold have been sequenced in the present investigation and enclosure of strain names in brackets indicates sequence identity to the previous strain listed.

and Ursing (1981) (hydroxyapatite method). DNA reassociation values are shown in two supplementary tables in IJSEM Online, including published data. These data are illustrated as a single linkage dendrogram in Fig. 3. Strains of biovars 1,9,10,11 and 19, including the type strain of [P.] aerogenes, linked at $70 \%$ DNA reassociation, while members of biovars 2, 6, 7, 8, 12, 15 and 21 linked at $81 \%$ reassociation. Between the $[P$.] aerogenes group and type strain of [P.] mairii, a maximum of $47 \%$ DNA reassociation was observed, indicating that these taxa might be related at the genus level based on DNA-DNA hybridizations (Fig. 3).

Two species-like groups were outlined. One included biovars $1,9,10,11$ and 19 of $[P$.$] aerogenes, while the$ other included biovars $2,6,7,8,12,15$ and 21 . The second group was closely related to the type strain of [A.] rossii, since the strains analysed by both DNA-DNA hybridization and 16S rRNA gene sequence comparison showed at least $98 \cdot 1 \% 16 \mathrm{~S}$ rRNA gene sequence similarity to the type strain of [A.] rossii. The DNA-DNA hybridization between the two groups was only $37 \%$, suggesting a genuslike difference (Fig. 3).

The relationship with biovars 16,18 and 20 and the relatedness between these biovars was at most $37 \%$, confirming the misidentification of these strains, since $16 \mathrm{~S}$ rRNA gene sequence analysis showed that strains of these biovars were closely related to A. equuli subsp. equuli, taxon 10 of Bisgaard and M. varigena.

\section{Emendation of the descriptions of $[P$.] aerogenes, $[P$.] mairii and [A.] rossii}

Strains characterized by $16 \mathrm{~S}$ rRNA gene sequence comparison, DNA-DNA hybridization as well as strains grouped by the RAPD analysis were all characterized phenotypically. Common characters for all strains of $[P$.] aerogenes, $[P$.$] mairii and [A.] rossii investigated (Table 1) were$ Gram-negative staining and lack of motility at 22 and $37^{\circ} \mathrm{C}$. The Hugh \& Leifson fermentation test with $(+)-\mathrm{D}-$ glucose was positive. Symbiotic growth (NAD requirement) was negative. The porphyrin test was positive. No growth was observed on Simmons' citrate agar and acid was not formed from mucate; an alkaline reaction was not seen in malonate broth. The $\mathrm{H}_{2} \mathrm{~S} / \mathrm{TSI}$ and $\mathrm{KCN}$ tests were negative. The Voges-Proskauer test at $37^{\circ} \mathrm{C}$ was also negative. Nitrate was reduced without gas formation. Urease and alanine aminopeptidase tests were positive. Tests for 


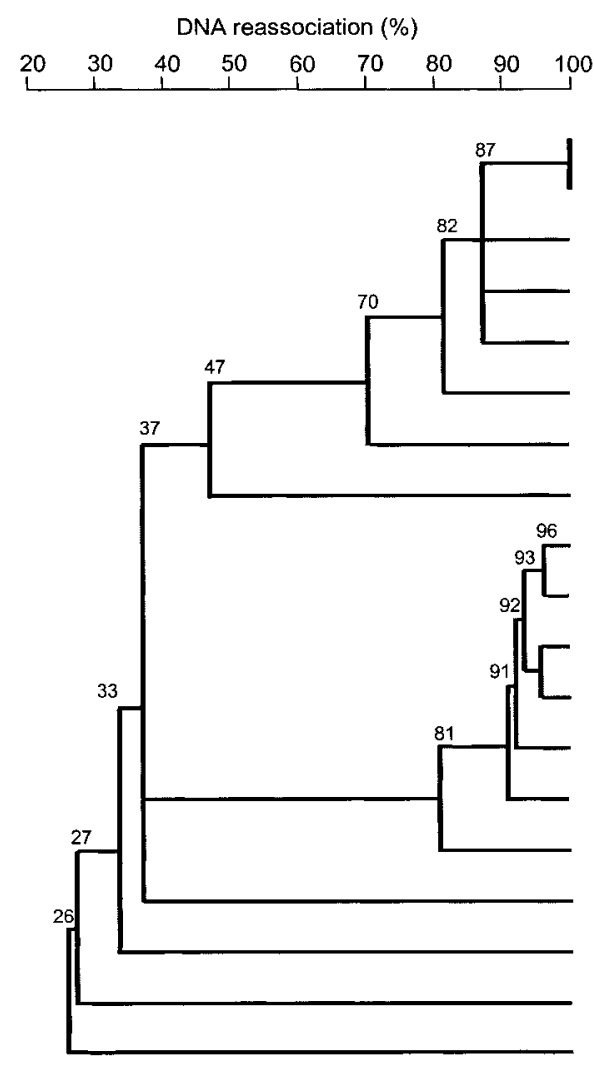

Phenoptypic identification

[P.] aerogenes ATCC $27883^{\top}$, bv. 1

[P.] aerogenes $3214 / 88$, bv. 2

$[P$.$] aerogenes P 591$, bv. 10

$[P$.$] aerogenes P.a.14, bv. 1$

$[P$.] aerogenes BK1778/4, bv. 19

$[P$.] aerogenes P592, bv. 11

$[P$.$] aerogenes \mathrm{P} 593$, bv. 11

[P.] mairii NCTC $10699^{\top}$

$[P$.$] aerogenes P.2, bv. 2$

$[P$.$] aerogenes \mathrm{P} 24$, bv. 7

$[P$.] aerogenes BA657/3, bv. 12

$[P$.$] aerogenes BK2661/4, bv. 21$

[P.] aerogenes 1989-5477, bv. 8

[P.] aerogenes P595, bv. 6

[P.] aerogenes P.a.7, bv. 15

[P.] aerogenes BA436.5, bv. 18

[P.] aerogenes BA597/9, bv. 20

P. multocida NCTC $10322^{\top}$

[P.] aerogenes 51811/78, bv. 16
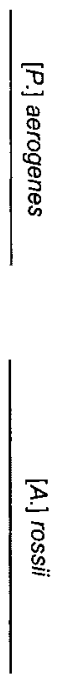

Bisgaard taxon 10

Mannheimia sp.

Actinobacillus sp.

Fig. 3. Relationships between strains of the $[P$.$] aerogenes-[P.] mairii-[A.] rossii complex based on pairwise DNA-DNA$ hybridization experiments. Data were obtained from the present investigation by the spectrophotometric method and from Böhme (1993) and Ursing (1981). The dendrogram was constructed by single-linkage clustering based on the DNA reassociations shown in two supplementary tables in IJSEM Online.

arginine dehydrolase, lysine decarboxylase and phenylalanine deaminase were negative. The three species were gelatinase-negative and did not hydrolyse Tween 20 or 80 . Pigment was not formed. Acid was not produced from meso-erythritol, adonitol, xylitol, (-)-L-xylose, dulcitol, ( + )-D-fucose, (-)-L-sorbose, cellobiose, trehalose, ( + )-Dmelezitose, (+)-D-glycogen, inulin, aesculin, amygdalin, arbutin, gentiobiose, salicin, (+)-D-turanose and $\beta-N$ $\mathrm{CH}_{3}$-glucosamid. Acid was produced from (-)-D-ribose, $(-)$-D-fructose, (-)-L-fucose and (+)-D-glucose. The ONGP test ( $\beta$-galactosidase tested with $o$-nitrophenyl Dgalactopyranoside) was positive. Tests for $\alpha$-fucosidase and $\alpha$-mannosidase were negative.

All except a single isolate of [A.] rossii produced acid from $(+)$-D-galactose, while only a single isolate was PNPG positive ( $\alpha$-glucosidase activity tested by 4 -nitrophenyl $\alpha$-Dglucopyranoside as substrate). Using the limits that positive or negative reactions refer to $90 \%$ of strains, these tests were excluded from Table 3, in which characters that separate the three taxa are stated. From this table, it is noted that at least four characters separate $[P$.] aerogenes from $[P$.$] mairii and [P$.$] mairii from [A$.$] rossii, while not$ even a single character allows a clear-cut separation of
$[P$.$] aerogenes from [A.] rossii. However, a combination of$ ornithine decarboxylase, production of indole and acid from (-)-D-mannitol, (-)-D-sorbitol, (+)-D-melibiose and raffinose separates these taxa.

The present study showed that phenotypic characterization was insufficient for classification and identification of porcine members of the $[P$.] aerogenes- $[P$.$] mairii- [$ A.] rossii complex. Comparison of $16 \mathrm{~S}$ rRNA gene sequences showed that $[P$.] aerogenes should be restricted to only 11 biovars, whereas 12 other biovars showed high 16S rRNA gene sequence similarity to the type strain of [A.] rossii. Finally, four biovars were found to be unrelated to $[P$.] aerogenes and [A.] rossii by $16 \mathrm{~S}$ rRNA gene sequence comparison, but related to other taxa of the Pasteurellaceae including Actinobacillus sensu stricto, Mannheimia and taxon 10 of Bisgaard. Both $A$. equuli subsp. equuli and $M$. varigena have been isolated from pigs. [P.] aerogenes biovar 16 was recorded as producing gas from $(+)$-D-glucose. However, reinvestigations showed that gas production could not be reproduced and misidentification is explained as the presence of gas in the Durham tube before inoculation. Biovar 18 was $(-)$-D-mannitol- and phosphatase-negative and (-)-L-fucose-positive, characters not previously 
reported for A. equuli. Only differences in phosphatase and formation of gas from glucose separate taxon 10 from A. equuli sensu stricto. For the same reasons, biovar 18 might be regarded as a (-)-D-mannitol-negative taxon 10 (M. Bisgaard, unpublished results). Biovar 17 differs from taxon 10 (CCUG 15572) only in (-)-D-mannitol and from biovar 18 in $(+)$-L-rhamnose. Similar phenotypic characters were, however, observed for biovar 17 and taxon 6 of Bisgaard. DNA-DNA hybridizations are needed to resolve the taxonomic positions of these taxa. Several phenotypic characters $[\beta$-haemolysis, methyl red, urease, $(+)$-Dmannose, PNPG and ONPF] separate biovar 20 from $M$. varigena biovar 1 . ONPF is testing for $\alpha$-fucosidase activity and was performed with 2-nitrophenyl $\alpha$-L-fucopyranoside.

Strains JF2006, JF1319, JF2032 and JF2118 of [P.] aerogenes with the RTX toxin (pax gene) (Kuhnert et al., 2000) could not be separated from the other strains based on 16S rRNA gene sequence comparison.

Polyamine profiles have been reported for two strains of [P.] aerogenes; however, strain BK1778/4 of biovar 19 differed significantly from the type strain. In the type strain, spermidine occurred in the highest proportion followed by putrescine, but in the other strain, BK1778/4, 1,3-diaminopropane was dominant, making up around $90 \%$ of all polyamines (Busse et al., 1997). The results might be explained if the strains had been misidentified; however, strain BK1778/4 was included in the present study and found to give a DNA-DNA reassociation value of $87 \%$ with the type strain of [P.] aerogenes. Further investigations are needed to solve this problem. In the type strain of $[A$.$] rossii and in strain BK2661.4 of biovar$ 21, 1,3-diaminopropane dominated, with $94 \cdot 7$ and $91 \cdot 0 \%$ of polyamines, respectively. This similarity was in accordance with a $16 \mathrm{~S}$ rRNA gene sequence similarity of $99 \cdot 1 \%$ between these two strains. For the type strain of [P.] mairii, 1,3-diaminopropane and putrescine constituted $47 \cdot 7$ and $43 \%$ of the total polyamine content, respectively, diverging significantly from the strains of $[P$.] aerogenes and $[A$.$] rossii$ characterized.

Human isolates obtained from infections related to pig bites seem to be related to biovar 17 of $[P$.] aerogenes (Lester et al., 1993; Lindberg et al., 1998), although their phenotype was also reportedly related to that of taxon 6 of Bisgaard (Bisgaard et al., 1983), a taxon otherwise isolated only from guinea pigs. In addition, taxon 6 of Bisgaard could not be separated phenotypically from biovar 17 in the present study. Finally, the SP group strains MCCM 00489 and MCCM 02119, which are phenotypically related to Bisgaard taxon 6 (M. Bisgaard, unpublished results), showed polyamine patterns related to $[A$.] rossii, with $1,3-$ diaminopropane dominance of around $92 \%$ (Busse et al., 1997). The identification of a strain of biovar 17 of [P.] aerogenes by $16 \mathrm{~S}$ rRNA gene sequence comparison as a misidentified strain of taxon 10 of Bisgaard could indicate that the human isolates might also belong to this taxon, since $98.9 \%$ similarity was reported between strain JF2423
(=P.a.3) of the present study and taxon 6 of Bisgaard. Exactly the same $16 \mathrm{~S}$ rRNA gene sequence similarity was found between taxa 6 and 10 of Bisgaard.

Ribotyping (RFLP with EcoRI probed by 16S-23S Escherichia coli rRNA) of 20 of the strains in the present study was able to separate the strains into groups with similarity to $[P$.$] aerogenes or [A$.$] rossii as well as separating the diver-$ gent biovars 16, 17, 18 and 20 (M. Bisgaard, unpublished results). Previously, ribotyping with the application of EcoRI was reported by Lester et al. (1993). Five of the strains investigated in the present study (P591 of biovar 10, P592 and P593 of biovar 11, P595 of biovar 6 and the type strain $\mathrm{P} 634^{\mathrm{T}}$ of $[P$.] aerogenes) belonged to two clusters related at $57 \%$ similarity only. Strains of biovar 10 and 11 were related to the type strain of $[P$.$] aerogenes at 92 \%$ similarity, while the strain of biovar 6 (shown to represent [A.] rossii in the present study) clustered at $57 \%$ (Lester et al., 1993). In the present study, strains of biovars 10 and 11 showed $99 \cdot 8 \% 16 \mathrm{~S}$ rRNA gene sequence similarity to the type strain of $[P$.] aerogenes, whereas biovar 6 was related to the type strain of $[P$.] aerogenes with $95 \cdot 1 \%$ similarity only. It can be concluded that ribotyping with EcoRI is a reliable tool for separation of isolates related to either $[P$. aerogenes or [A.] rossii.

Based on the present emended description of the three species $[P$.] aerogenes, $[P$.$] mairii and [A$.$] rossii, it would be$ tempting to re-evaluate published phenotypic data by Ross et al. (1972), Sneath \& Stevens (1985), McAllister \& Carter (1974) and Fodor et al. (1991) on these species. However, such a comparison is difficult for several reasons. First of all, methods might differ slightly. As examples, an important character such as $\beta$-haemolysis depends on the type of blood (bovine or ovine) and medium used, including $\mathrm{pH}$ (M. Bisgaard, unpublished observation). In addition, the outcome of the phosphatase test seems to depend on the type of test used (see Table 3). Another problem is that the original data do not include results for single strains, which is a precondition for clear-cut comparisons.

Ward et al. (1998) reported on equine isolates of [P.] mairii; however, the strains differed in trehalose, lactose and salicin according to the present description of $[P$. $]$ mairii. For the same reasons, identification of isolates of $[P$.] mairii from horses should be questioned unless genetic data confirm their classification.

The accuracy of the present characterization was evaluated by the inclusion of three different designations of the type strain of $[P$.$] mairii. Both phenotypic and RAPD character-$ ization of strains $\mathrm{P} 637^{\mathrm{T}}$, Mair5143/70 ${ }^{\mathrm{T}}$ and NCTC $10699^{\mathrm{T}}$ showed identical results.

The three taxa $[P$.$] aerogenes, [P$.$] mairii and [A$.$] rossii$ can probably not be separated on the basis of DNA G $+C$ content or genome size. The DNA G+C content of the type strain of $[P$.] aerogenes was $41.8 \mathrm{~mol} \%$ (Mutters et al., 1985), with a genome size of $1 \cdot 6-2 \cdot 0 \mathrm{GDa}$ (Mutters et al., 
2004). The DNA G $+\mathrm{C}$ content of the type strain of $[P$. mairii was $43.4 \mathrm{~mol} \%$ and the genome size $1.9 \mathrm{GDa}$ (Mutters et al., 1985; Piechulla et al., 1985), and the DNA $\mathrm{G}+\mathrm{C}$ content of the type strain of [A.] rossii was $41.9 \mathrm{~mol} \%$ with a genome size of $1.8 \mathrm{GDa}$ (Piechulla et al., 1985). For two other strains related to [A.] rossii by $16 \mathrm{~S}$ rRNA gene sequence comparison, slightly lower DNA G $+C$ contents but larger genome sizes were found in the present study. The DNA G + C content of strain P.24 of [A.] rossii ([P.] aerogenes biovar 7) was $40.5 \mathrm{~mol} \%$, with a genome size of $2.5 \mathrm{GDa}$, and the DNA G $+\mathrm{C}$ content of strain BA657/3 of $[A$.$] rossii ([P.] aerogenes biovar 12)$ was $39 \mathrm{~mol} \%$ and the genome size was $2 \cdot 2 \mathrm{GDa}$.

Based on the unique phylogenetic position of [P.] aerogenes, $[P$.] mairii and $[A$.] seminis, making up the Seminis group inferred from $16 \mathrm{~S}$ rRNA gene sequence comparison (Christensen et al., 2003; Olsen et al., 2004), this group might deserve genus rank. With the emended description of $[P$.$] aerogenes in the present study, this species showed$ $95 \cdot 5-97 \cdot 2 \% 16 \mathrm{~S}$ rRNA gene sequence similarity to the emended $[P$.$] mairii, while this taxon showed 97 \cdot 6-97 \cdot 7 \%$ similarity to the type strain of [A.] seminis. Unfortunately data are missing to document fully the relationships between $[P$.] aerogenes, $[P$.] mairii and $[A$.$] seminis, since$ [A.] seminis has not been extensively characterized phenotypically and DNA-DNA hybridizations have not been made between this taxon and $[P$.] aerogenes and $[P$.] mairii. With the exception of a negative reaction in urease and ONPG and differences in colonial morphology, [A.] seminis shares the common phenotypic properties for $[P$.] aerogenes, $[P$.] mairii and $[A$.$] rossii given in the present paper$ (M. Bisgaard, unpublished data). Characters that separate all four taxa are stated in Table 3. In addition, RAPD profiling seems to be a valuable tool to confirm the separation of the three species and their separation from [A.] seminis (see Fig. 1). However, until further information is provided, it is only possible to change the circumscription of the three species $[P$.] aerogenes, $[P$.] mairii and $[A$.$] rossii$ to improve the identification of these taxa and not to name a new genus. The major changes compared to the original descriptions (McAllister \& Carter, 1974; Kilian \& Frederiksen, 1981; Sneath \& Stevens, 1990) have been the extended number of strains characterized and different kinds of phenotypic properties evaluated. Few characters have changed compared with the original description; however, new characters useful for differentiation of the organisms have been added to the descriptions. Twelve characters (negative Gram stain, lack of motility at 22 and $37^{\circ} \mathrm{C}$, lack of growth in Simmons' citrate agar and acid formation from glucose, nitrate reduction, positive urease, negative lysine decarboxylase and gelatinase reactions and lack of acid production from dulcitol and salicin) were conserved between all three species and were in accordance with the original descriptions of McAllister \& Carter (1974) and Sneath \& Stevens (1990). A further 14, 28 and 31 reactions were in accordance with the original descriptions for each of the three species $[P$.$] aerogenes, [P$.$] mairii and$
[A.] rossii, respectively. However, 10, 18 and 15 reactions diverged from the original descriptions. This might be related to different numbers of strains investigated changing the positive and negative signs in relation to the tolerated limits of $10 \%$ variation allowed for a reaction. Different methods or variation in methods might also account for the variation and, finally, phenotypic characterization might have diverged from the 16S rRNA-based identification in previous studies, as already discussed. For 44, 22 and 22 characters, respectively, new information was provided for the three species $[P$.$] aerogenes, [P$.$] mairii and [A$.$] rossii.$

$16 \mathrm{~S}$ rRNA gene sequence-based phylogenetic analysis has indicated that $[A$.$] rossii and [A.] porcinus form a genus-like$ group (Christensen et al., 2003; Olsen et al., 2004). Comparison of phenotypic characteristics of $[A$.$] rossii with$ the type strain of $[A$.$] porcinus showed divergence in$ seven characters. Reactions of three divergent characters [phosphatase, glycerol and (+)-L-arabinose] are shown in Table 3. In addition, the type strain of [A.] porcinus was NAD-requiring, urease-negative, without ability to form acid from (-)-D-ribose and ONPF-positive compared with $[A$.$] rossii and also [P$.$] aerogenes and [P$.$] mairii, being$ without NAD requirement, urease-positive, with ability to form acid from (-)-D-ribose and ONPF-negative. Since only the type strain of [A.] porcinus has been characterized in detail, it is not currently possible to consider whether the Rossii 16S rRNA group can be named as a new genus; however, the distinctiveness of [A.] rossii and [A.] porcinus at the species level has been verified.

The type strain of [A.] porcinus has previously been characterized by Møller et al. (1996) and Kielstein et al. (2001) and agreement was found for 30 of 31 characters; for (-)-Dfructose, we determined a positive reaction compared with the negative result determined by Kielstein et al. (2001).

\section{Emended description of [Pasteurella] aerogenes McAllister and Carter 1974}

[Pasteurella] aerogenes (ae.ro.ge'nes. Gr. subst. masc. aeros air; Gr. subst. neut. genos generating; N.L. subst. aerogenes air-generating).

Cellular and colonial morphologies are as reported by McAllister \& Carter (1974). Cells on blood agar are 0.5$1.0 \mu \mathrm{m}$ wide and $1 \cdot 1-2 \cdot 0 \mu \mathrm{m}$ long with filaments seen, especially in older cultures. After $24 \mathrm{~h}$ incubation on bovine blood agar, colonies are circular, smooth, convex, regular and greyish, $0.5-1.0 \mathrm{~mm}$ in diameter. Haemolysis is not observed on bovine blood agar. Cells are Gram-negatively stained and do not show motility at 22 or $37^{\circ} \mathrm{C}$. Catalase reaction is positive. Hugh \& Leifson fermentation test with (+)-D-glucose is positive. Symbiotic growth (NAD requirement) is negative. Porphyrin test is positive. No growth is observed on Simmons' citrate agar and acid is not formed from mucate; alkaline reaction is not seen in malonate broth. $\mathrm{H}_{2} \mathrm{~S} / \mathrm{TSI}$ and KCN tests are negative. Voges-Proskauer test at $37^{\circ} \mathrm{C}$ is also negative. Nitrate is 
reduced without gas formation. Urease and alanine aminopeptidase tests are positive. Tests for arginine dehydrolase, lysine decarboxylase and phenylalanine deaminase are negative and so are tests for indole and phosphatase. The species is gelatinase-negative and does not hydrolyse Tween 20 or 80 . Growth on MacConkey is positive. Pigment is not formed. Acid is not produced from meso-erythritol, adonitol, (+)-D-arabitol, xylitol, (-)-L-xylose, dulcitol, (-)-D-sorbitol, (+)-D-fucose, (+)-L-rhamnose, (-)-Lsorbose, cellobiose, (+)-D-melibiose, trehalose, (+)-Dmelezitose, (+)-D-glycogen, inulin, aesculin, amygdalin, arbutin, gentiobiose, salicin, (+)-D-turanose or $\beta-N-\mathrm{CH}_{3}-$ glucosamid. Acid is produced from glycerol, (-)-Darabinose, (-)-D-ribose, meso-inositol, (-)-D-fructose, $(-)$-L-fucose, (+)-D-galactose, (+)-D-glucose, ( + )-Dmannose, lactose, maltose, sucrose and dextrin. The ONGP test is positive. Tests for $\alpha$-fucosidase, $\alpha$-mannosidase and $\alpha$-galactosidase and PNPG are negative. The oxidase, methyl red, ornithine decarboxylase, NPG ( $\beta$-glucosidase test determined by 4 -nitrophenyl $\beta$-D-glucopyranoside), PGUA ( $\beta$-glucuronidase reaction determined by 4 -nitrophenyl $\beta$-D-glucopyranosiduronic acid) and ONPX ( $\beta$-xylosidase test performed with 2 -nitrophenyl $\beta$-D-xylopyranoside) reactions are isolate-dependent in addition to production of acid from (+)-L-arabinose, (+ )-D-xylose, (-)-D-mannitol, raffinose, hydrolysis of aesculin and gas formation from glucose. It is recommended to use supplementary genotyping methods in the identification of this species, e.g. 16S rRNA gene sequencing or ribotyping. The bacteria are mostly reported from pigs and infrequently from rabbit, dog and humans bitten by pigs. The bacteria have been isolated from tonsils, lung, bronchia, intestines, placenta, stomach of aborted pigs, joint, liver and lymph nodes and associated with sepsis, pneumonia and diarrhoea.

The type strain is ATCC $27883^{\mathrm{T}}\left(=\mathrm{CCUG} 9995^{\mathrm{T}}=\mathrm{CIP}\right.$ $80.14^{\mathrm{T}}=\mathrm{DSM} 10153^{\mathrm{T}}$ ), isolated from pig intestine in USA. The DNA G + C content of the type strain is $41.8 \mathrm{~mol} \%$ (Mutters et al., 1985) and the genome size is $1 \cdot 6-2 \cdot 0 \mathrm{GDa}$ (Mutters et al., 2004).

\section{Emended description of [Pasteurella] mairii Sneath and Stevens 1990}

[Pasteurella] mairii (mair'i.i. N.L. gen. n. mairii of Mair).

Cellular and colony morphologies are mostly as previously reported by Sneath \& Stevens (1990). Cells are small, nonmotile bacilli or coccobacilli, mostly shorter than $1 \mu \mathrm{m}$ and not more than $0.5 \mu \mathrm{m}$ wide, occurring singly or as filaments. Colonies on bovine blood agar are regular, circular and convex, greyish, semi-transparent and approx. $1-1.5 \mathrm{~mm}$ in diameter after $24 \mathrm{~h}$ incubation at $37^{\circ} \mathrm{C}$. Haemolysis is normally not seen but may be observed, mainly under the colonies. Cells are Gram-negative and do not show motility at 22 or $37^{\circ} \mathrm{C}$. Catalase reaction is positive. Hugh \& Leifson fermentation test with $(+)$-Dglucose is positive. Symbiotic growth (NAD requirement) is negative. Porphyrin test is positive. No growth is observed on Simmons' citrate agar and acid is not formed from mucate; an alkaline reaction is not seen in malonate broth. $\mathrm{H}_{2} \mathrm{~S} / \mathrm{TSI}$ and $\mathrm{KCN}$ tests are negative. Methyl red and VogesProskauer tests at $37^{\circ} \mathrm{C}$ are also negative. Nitrate is reduced without gas formation. Urease and alanine aminopeptidase test are positive. Tests for arginine dehydrolase, lysine decarboxylase and phenylalanine deaminase are negative. Ornithine decarboxylase and phosphatase tests are positive. Indole and gelatinase tests are negative and members of the species do not hydrolyse Tween 20 or 80 . Growth on MacConkey is negative and pigment is not formed. Acid is not produced from meso-erythritol, adonitol, xylitol, $(-)$ D-arabinose, (-)-L-xylose, dulcitol, ( + )-D-fucose, $(+)$-Lrhamnose, (-)-L-sorbose, cellobiose, lactose, maltose, $(+)$-D-melibiose, trehalose, (+)-D-melezitose, raffinose, dextrin, (+)-D-glycogen, inulin, aesculin, amygdalin, arbutin, gentiobiose, salicin, (+)-D-turanose or $\beta$-N$\mathrm{CH}_{3}$-glucosamid. Acid is produced from $(+)$-L-arabinose, (+)-D-xylose, (-)-D-ribose, meso-inositol, (-)-D-mannitol, $(-)$-D-sorbitol, (-)-D-fructose, (-)-L-fucose, (+)-Dgalactose, $(+)$-D-glucose (without gas), $(+)$-D-mannose and sucrose. ONGP, NPG and PGUA tests are positive. Tests for $\alpha$-fucosidase, $\alpha$-mannosidase, $\alpha$-galactosidase and PNPG are negative. Aesculin is hydrolysed. Oxidase and ONPX reactions are isolate-dependent and so is acid formation from glycerol and (+)-D-arabitol. It is recommended to use supplementary genotyping methods in the identification of this species, e.g. 16S rRNA gene sequencing and RAPD DNA fingerprinting. The bacteria have been isolated from the reproductive tract and from aborted pigs.

The type strain is NCTC $10699^{\mathrm{T}}$ (=CCUG $27189^{\mathrm{T}}$ ), isolated from a pig fetus in the UK. The DNA G + C content of the type strain is $43.4 \mathrm{~mol} \%$ and the genome size is 1.9 GDa (Mutters et al., 1985; Piechulla et al., 1985).

\section{Emended description [Actinobacillus] rossii Sneath and Stevens 1990}

[Actinobacillus] rossii (ross'i.i. N.L. gen. n. rossii of Ross).

Cellular and colony morphologies are mostly as reported previously by Sneath \& Stevens (1990). Cells are mostly small bacilli, rarely coccobacilli, less than $2 \mu \mathrm{m}$. Colonies on bovine agar are circular, regular, convex and greyish and semi-transparent and about $1-2 \mathrm{~mm}$ in diameter after $24 \mathrm{~h}$ incubation at $37^{\circ} \mathrm{C}$. $\beta$-Haemolysis is not commonly observed. Cells are Gram-negatively stained and do not show motility at 22 or $37^{\circ} \mathrm{C}$. Hugh \& Leifson fermentation test with $(+)$-D-glucose is positive. Symbiotic growth (NAD requirement) is negative. Porphyrin test is positive. No growth is observed on Simmons' citrate agar and acid is not formed from mucate; an alkaline reaction is not seen in malonate broth. $\mathrm{H}_{2} \mathrm{~S} / \mathrm{TSI}$ and $\mathrm{KCN}$ tests are negative. Voges-Proskauer test at $37^{\circ} \mathrm{C}$ is also negative. Nitrate is reduced without gas formation. Urease and alanine aminopeptidase test are positive. Tests for arginine dehydrolase, lysine decarboxylase, ornithine decarboxylase and phenylalanine deaminase are negative. Phosphatase test is negative. 
The species is gelatinase-negative and does not hydrolyse Tween 20 or 80 . Pigment is not formed. Acid is not produced from meso-erythritol, adonitol, xylitol, (-)-L-xylose, dulcitol, ( +)-D-fucose, $(-)$-L-sorbose, cellobiose, trehalose, $(+)$-D-melezitose, (+)-D-glycogen, inulin, aesculin, amygdalin, arbutin, gentiobiose, salicin, $(+)$-D-turanose or $\beta-N-\mathrm{CH}_{3}$-glucosamid. Acid is produced from glycerol, (+)L-arabinose, (-)-D-ribose, (-)-D-mannitol, (-)-D-fructose, $(-)$-L-fucose, $(+)$-D-galactose, $(+)$-D-glucose and lactose. ONGP test is positive. Tests for $\alpha$-fucosidase, $\alpha$-glucosidase, PNPG and $\alpha$-mannosidase are negative. Catalase, oxidase, methyl red, indole, growth on MacConkey agar, NPG, $\alpha$-galactosidase, PGUA and ONPX reactions are isolatedependent, as are acid formation from $(+)$-L-arabitol, $(-)$-D-arabinose, (+)-D-xylose, meso-inositol, (-)-sorbitol, (+)-mannose, (+)-L-rhamnose, maltose, (+)-D-melibiose, sucrose, raffinose and dextrin and gas formation from glucose. It is recommended to use supplementary genotyping methods in the identification of this species, e.g. 16S rRNA gene sequencing, RAPD and ribotyping. The bacteria have been isolated from vaginal exudate, abortion, tonsils, lungs, liver, intestines, bone and brain of pigs.

The type strain is ATCC $27072^{\mathrm{T}}\left(=\right.$ CCUG $12395^{\mathrm{T}}=$ NCTC $10801^{\mathrm{T}}=$ CIP $\left.102634^{\mathrm{T}}\right)$, isolated from vaginal exudates of a pig in the USA. The DNA G + C content is $39-41.9 \mathrm{~mol} \%$ and the genome size is $2 \cdot 2-2 \cdot 5 \mathrm{GDa}$.

\section{Acknowledgements}

Tony Bønnelycke and Louise Juul Møller are thanked for excellent technical assistance. This project was financed by the Danish Agricultural and Veterinary Research Council grant no. 9702797.

\section{References}

Altschul, S. F., Madden, T. L., Schaffer, A. A., Zhang, J., Zhang, Z., Miller, W. \& Lipman, D. J. (1997). Gapped BLAST and PSI-BLAST: a new generation of protein database search programs. Nucleic Acids Res 25, 3389-3402.

Angen, Ø., Ahrens, P. \& Tegtmeier, C. (1998). Development of a PCR test for identification of Haemophilus somnus in pure and mixed cultures. Vet Microbiol 63, 39-48.

Bisgaard, M. (1993). Ecology and significance of Pasteurellaceae in animals. Zentbl Bakteriol 279, 7-26.

Bisgaard, M., Mutters, R. \& Mannheim, W. (1983). Characterization of some previously unreported taxa isolated from guinea pigs (Cavia procellus) and provisionally classed with the "HPA-group". INSEM 114, 227-244.

Bisgaard, M., Houghton, S. B., Mutters, R. \& Stenzel, A. (1991). Reclassification of German, British and Dutch isolates of so-called Pasteurella multocida obtained from pneumonic calf lungs. Vet Microbiol 26, 115-124.

Böhme, A. (1993). Zelluläre Kohlenhydrate und Genomverwandtschaften bei Pasteurella aerogenes und ähnlichen Isolaten. Marburg: Fachbereich Biologie der Philipps-Universität (in German).

Busse, H.-J., Bunka, S., Hensel, A. \& Lubitz, W. (1997). Discrimination of members of the family Pasteurellaceae based on polyamine patterns. Int J Syst Bacteriol 47, 698-708.
Christensen, J. P., Olsen, J. E. \& Bisgaard, M. (1993). Ribotypes of Salmonella enterica serovar Gallinarum biovars gallinarum and pullorum. Avian Pathol 22, 725-738.

Christensen, H., Bisgaard, M., Angen, Ø. \& Olsen, J. E. (2002). Final classification of Bisgaard taxon 9 in the novel species Actinobacillus arthritidis sp. nov., and proposal of genomospecies 1 for equine $A$. lignieresii. Int J Syst Evol Microbiol 52, 1239-1246.

Christensen, H., Foster, G., Christensen, J. P., Olsen, J. E. \& Bisgaard, M. (2003). Characterization of bacteria associated with birds including phylogenetic analysis by $16 \mathrm{~S}$ rRNA sequence comparison and the description of two new taxa of Pasteurellaceae. J Appl Microbiol 95, 354-363.

De Ley, J., Mannheim, W., Mutters, R. \& 7 other authors (1990). Inter- and intrafamilial similarities of rRNA cistrons of the Pasteurellaceae. Int J Syst Bacteriol 40, 126-137.

Dziva, F., Christensen, H., Olsen, J. E. \& Mohan, K. (2001). Random amplification of polymorphic DNA and phenotypic typing of Zimbabwean isolates of Pasteurella multocida. Vet Microbiol 82, 361-372.

Felsenstein, J. (1981). Evolutionary trees from DNA sequences: a maximum likelihood approach. J Mol Evol 17, 368-376.

Felsenstein, J. (1995). PHYLIP (phylogeny inference package), version 3.57c. Distributed by the author. Department of Genetics, University of Washington, Seattle, USA.

Fodor, L., Hajtos, I. \& Glavits, R. (1991). Abortion of a sow caused by Pasteurella aerogenes. Acta Vet Hung 39, 13-19.

Hommez, J. \& Devriese, L. A. (1976). Pasteurella aerogenes isolations from swine. Zentbl Veterinaermed B 23, 265-268.

Kielstein, P., Wuthe, H., Angen, Ø., Mutters, R. \& Ahrens, P. (2001). Phenotypic and genetic characterization of NADdependent Pasteurellaceae from the respiratory tract of pigs and their possible pathogenetic importance. Vet Microbiol 81, 243-255.

Kilian, M. \& Frederiksen, W. (1981). Identification tables for the Haemophilus-Pasteurella-Actinobacillus group. In Haemophilus, Pasteurella and Actinobacillus, pp. 281-290. Edited by M. Kilian, W. Frederiksen \& E. L. Biberstein. London: Academic Press.

Kuhnert, P., Heyberger-Meyer, B., Nicolet, J. \& Frey, J. (2000). Characterization of PaxA and its operon: a cohemolytic RTX toxin determinant from pathogenic Pasteurella aerogenes. Infect Immun 68, 6-12.

Lester, A., Gerner-Smidt, P., Gahrn-Hansen, B., Søgaard, P., Schmidt, J. \& Frederiksen, W. (1993). Phenotypical characters and ribotyping of Pasteurella aerogenes from different sources. Zentbl Bakteriol 279, 75-82.

Lindberg, J., Frederiksen, W., Gahrn-Hansen, B. \& Bruun, B. (1998). Problems of identification in clinical microbiology exemplified by pig bite wound infections. Zentbl Bakteriol 288, 491-499.

McAllister, H. A. \& Carter, G. R. (1974). An aerogenic Pasteurellalike organism recovered from swine. Am J Vet Res 35, 917-922.

Møller, K., Fussing, V., Grimont, P. A. D., Paster, B. J., Dewhirst, F. E. \& Kilian, M. (1996). Actinobacillus minor sp. nov., Actinobacillus porcinus sp. nov., and Actinobacillus indolicus sp. nov., three new $\mathrm{V}$ factor-dependent species from the respiratory tract of pigs. Int J Syst Bacteriol 46, 951-956.

Mutters, R., Ihm, P., Pohl, S., Frederiksen, W. \& Mannheim, W. (1985). Reclassification of the genus Pasteurella Trevisan 1887 on the basis of deoxyribonucleic acid homology, with proposals for the new species Pasteurella dagmatis, Pasteurella canis, Pasteurella stomatis, Pasteurella anatis, and Pasteurella langaa. Int J Syst Bacteriol 35, 309-322. 
Mutters, R., Mannheim, W. \& Bisgaard, M. (1989). Taxonomy of the group. In Pasteurella and Pasteurellosis, pp. 3-34. Edited by C. Adlam \& J. M. Rutter. London: Academic Press.

Mutters, R., Christensen, H. \& Bisgaard, M. (2004). Genus Pasteurella Trevisan 1887, $94^{\mathrm{AL}}$ Nom. cons. Opin. 13, Jud. Comm. 1954. In Bergey's Manual of Systematic Bacteriology, 2nd edn, vol. 2. Edited by G. R. Garrity. New York: Springer (in press).

Olsen, G. J., Matsuda, H., Hagstrom, R. \& Overbeek, R. (1994). FastDNAml: a tool for construction of phylogenetic trees of DNA sequences using maximum likelihood. Comput Appl Biosci 10, 41-48.

Olsen, I., Dewhirst, F. E., Paster, B. J. \& Busse, H.-J. (2004). Family Pasteurellaceae. In Bergey's Manual of Systematic Bacteriology, 2nd edn, vol. 2. Edited by G. R. Garrity. New York: Springer (in press).

Piechulla, K., Bisgaard, M., Gerlach, H. \& Mannheim, W. (1985). Taxonomy of some recently described avian Pasteurella/Actinobacilluslike organisms as indicated by deoxyribonucleic acid relatedness. Avian Pathol 14, 281-311.

Ross, R. F., Hall, J. E., Orning, A. P. \& Dale, S. E. (1972). Characterization of an Actinobacillus isolated from the sow vagina. Int J Syst Bacteriol 22, 39-46.
Schaller, A., Kuhnert, P., Puente-Redondo, V. A., de la Nicolet, J. \& Frey, J. (2000). Apx toxins in Pasteurellaceae species from animals. Vet Microbiol 74, 365-376.

Skerman, V. B. D., McGowan, V. \& Sneath, P. H. A. (1980). Approved lists of bacterial names. Int J Syst Bacteriol 30, 225-420.

Sneath, P. H. A. \& Stevens, M. (1985). A numerical taxonomic study of Actinobacillus, Pasteurella and Yersinia. J Gen Microbiol 131, 2711-2738.

Sneath, P. H. A. \& Stevens, M. (1990). Actinobacillus rossii sp. nov., Actinobacillus seminis sp. nov., nom. rev., Pasteurella bettii sp. nov., Pasteurella lymphangitidis sp. nov., Pasteurella mairi sp. nov., and Pasteurella trehalosi sp. nov. Int J Syst Bacteriol 40, 148-153.

Ursing, J. (1981). Deoxyribonucleic acid hybridisation studies of gas producing pasteurellae. In Haemophilus, Pasteurella and Actinobacillus, pp. 255-263. Edited by M. Kilian, W. Frederiksen \& E. L. Biberstein. London: Academic Press.

Ward, C. L., Wood, J. L. N., Houghton, S. B., Mumford, J. A. \& Chanter, N. (1998). Actinobacillus and Pasteurella species isolated from horses with lower airway disease. Vet Rec 143, 277-279. 